\title{
Individual and spousal education, mortality and life expectancy in Switzerland: a national cohort study
}

\author{
Adrian Spoerri, ${ }^{1}$ Kurt Schmidlin, ${ }^{1}$ Matthias Richter, ${ }^{2}$ Matthias Egger, ${ }^{1}$ \\ Kerri M Clough-Gorr, ${ }^{1,3}$ for the Swiss National Cohort (SNC)
}

- Additional material is

published online only. To view please visit the journal online (http://dx.doi.org/10.1136/jech2013-203714).

1 Institute of Social and Preventive Medicine (ISPM), University of Bern, Bern, Switzerland 2Institute of Medical Sociology,
(IMS), Martin-Luther University, Halle, Germany

${ }^{3}$ Section of Geriatrics, Boston University School of Medicine, Boston Medical Center,

Boston, USA

\section{Correspondence to} Professor Kerri M Clough-Gorr, Institute of Social and

Preventive Medicine (ISPM), University of Bern,

Finkenhubelweg 11 Bern CH-3012, Switzerland: kclough@ispm.unibe.ch

\section{ABSTRACT \\ Background Household measures of socioeconomic position may better account for the shared nature of material resources, lifestyle, and social position of cohabiting persons, but household measures of education are rarely used. We aimed to evaluate the association of combined educational attainment of married couples on mortality and life expectancy in Switzerland. \\ Methods The study included 3496163 ever-married} persons aged $\geq 30$ years. The 2000 census was linked to mortality records through 2008. Mortality by combined educational attainment was assessed by gender-agespecific HRs, with 95\% Cls from adjusted models, life expectancy was derived using abridged life tables. Results Having a less educated partner was associated with increased mortality. For example, the HR comparing men aged 50-64 years with tertiary education married to women with tertiary education to men with compulsory education married to women with compulsory education was 2.05 (1.92-2.18). The estimated remaining life expectancy in tertiary educated men aged 30 years married to women with tertiary education was 4.6 years longer than in men with compulsory education married to women with compulsory education. The gradient based on individual education was less steep: the HR comparing men aged 50-64 years with tertiary education with men with compulsory education was 1.74 (1.67-1.81).

Conclusions Using individual educational attainment of married persons is common in epidemiological research, but may underestimate the combined effect of education on mortality and life expectancy. These findings are relevant to epidemiologic studies examining socio-demographic characteristics or aiming to adjust results for these characteristics.

\section{INTRODUCTION}

Education, occupation, income and wealth are core indictors of socioeconomic position (SEP) used in epidemiological research. ${ }^{1}$ Educational attainment measures have the advantage of being ordered by increasing levels, widely collected and predictive of income and wealth (ie, representing earning potential). ${ }^{1}$ Another benefit of using education in research settings is that it is less fluid than other SEP measures over time. In most cases education is completed in early-adulthood and does not change much in later life. Education can have an effect on health outcomes via multiple pathways. More highly educated persons are more inclined towards healthier lifestyles and have higher levels of health literacy and better access to healthcare. ${ }^{2-6}$ Education also provides formal qualifications for the labour market and can directly influence earning potential and the acquisition of material resources that influence health outcomes.

Measurement issues are critical in epidemiological research. Household measures of SEP, for example, household equivalent income or wealth are thought to better account for the shared nature of material resources, lifestyle, and social position of cohabiting persons. For education, household measures are rarely used. ${ }^{8}{ }^{9}$ Instead education is typically measured by highest achieved educational level of an individual. However, married couples and nuclear families share material resources, social privilege, and lifestyles when they live together. The impact of these shared health-related characteristics are unlikely to be fully reflected by an individual family member's education alone: it may be more comprehensively captured by the combined educational attainment of the married couple. Yet, few studies have looked at differences in mortality based on the combined education of married pairs. ${ }^{10} 11$ Studies generally use separate measures for each partner without considering modification of effects by combined education. Furthermore, results from large population-based studies using combined marital education that also examine life expectancy are even scarcer. ${ }^{12}$

Our aim was to use the data of the Swiss National Cohort (SNC), a comprehensive national longitudinal research platform, and evaluate mortality risk and life expectancy in Switzerland based on combined marital (individual and spouse) educational attainment. ${ }^{13}$ Our a priori hypothesis was that the education level of a spouse would be associated with their partner's mortality risk and life expectancy.

\section{METHODS}

Study population

The SNC has been described in detail elsewhere. ${ }^{13} 14$ In brief, the study used probabilistic record linkage to link 1990 and 2000 census records to Federal death or emigration records. ${ }^{15} 16$ Linkage was based on a set of key variables available in datasets (eg, sex, date of birth (DOB), place of residence, marital status, religion, nationality). Because participation in the Swiss census is mandatory, enumeration is virtually complete; coverage of the 2000 census was estimated at $99 \% .{ }^{17} 18$ The present analysis was based on the 2000 census population and included ever-married individuals aged 30 years or older, for two reasons: (1) 30 years is the age by which most tertiary education is completed in Switzerland, and (2) it reflects the average age at marriage (in 1960 31/27 years and 
2012 32/30 years, men/women respectively). ${ }^{19}$ We excluded all persons with no educational attainment information.

\section{Variables and definitions}

Marriage was defined as those married and living together at the 2000 census, or divorced and widowed at the 2000 census but married and living together at 1990 census. Educational attainment was defined by the most recent census data on education (ie, 2000 unless missing, then 1990). We grouped individual and spousal education into three categories: 'compulsory education' (compulsory schooling up to 9 years of education or less); 'secondary education' (high school, teachers training colleges, vocational education); and, 'tertiary education' (all university undergraduate, post-graduate, higher professional training). Combined education was defined by the nine possible categories of the married pair (individual-spouse): compulsory-compulsory, compulsory-secondary, compulsory-tertiary, secondarycompulsory, secondary-secondary, secondary-tertiary, tertiarycompulsory, tertiary-secondary, tertiary-tertiary.

Socio-demographic variables were from the 2000 census. We included gender, age at census, marital status (married/widowed/ divorced), duration of marriage ( $\leq 10$ years, $11-20$ years, $\geq 21$ years), nationality (Swiss/non-Swiss), language region (German/French/Italian), type of household (single-person/ multi-person/institution), urbanisation (urban/peri-urban/rural), religion (Protestant/Catholic/no affiliation/other-unknown). We categorised age as 30-49 years, 50-64 years, 65-79 years, and $80+$ years. Questionnaires and variable lists are available from the SNC website at http://www.swissnationalcohort.ch.

\section{Mortality}

Cause and date of death of all deaths between 5 December 2000 and 31 December 2008 were recorded from official Swiss death certificates. Since 1995, causes of death have been coded according to the tenth revision of the International Classification of Diseases, Injuries and Causes of Death (ICD-10). Cause-specific deaths included: all-cancer (ICD-10 C00-C97); colorectal cancer (ICD-10 C18-C21); breast cancer (ICD-10 C50); prostate cancer (ICD-10 C61); stomach cancer (ICD-10 C16); lung cancer (ICD-10 C33-C34); cardiovascular diseases (ICD-10 I00-I99); myocardial infarction (ICD-10 I21-I22); stroke (ICD-10 I60-I64); respiratory diseases (ICD-10 J00-J99); transport accidents (ICD-10 V01-V99); suicide (ICD-10 X60-X84); alcohol-related causes (ICD-10 F10, G31.2, G62.1, I42.6, K29.2, K70, K73, K74.0-K74.2, K74.6, K86.0, X45, X65, Y15); external causes without suicide (ICD-10 V01-V99, W00-W99, X00-X59, X85-X99, Y00-Y98). We used the underlying cause of death to determine the cause of death, except for alcohol-related deaths, which included any mention of an alcohol-related ICD-10 on the death certificate.

\section{Statistical analyses}

We calculated HRs of death from all causes and specific causes with 95\% CIs across educational categories using Cox proportional hazard regression models. We calculated time from the DOB of the individual and used age as the underlying timescale in all age-adjusted models. In persons aged 30 years or older time of observation was from the date of census (5 December 2000) to the date of death, emigration, or the end of the study period (31 December 2008), whichever occurred first. In those $<30$ years at census date time of observation started on the 30th birthday. The day a person reached an upper age-group limit their person-years were thereafter assigned to the next older age-group. Cox models were stratified by age-group and sex to examine effect modification. Final models included age in years, marital status, nationality, religion, type of household, language region, urbanisation, and calendar year.

To estimate life expectancy by educational attainment, we calculated mortality rates by gender, 5-year age-groups and combined education for ever-married persons. Using Chiang's method we constructed an abridged life table starting at age 30 years (conditioned on survival up to age 30 years) with the

Table 1 Socio-demographic characteristics at census 2000 of ever-married men and women aged 30 years or older, N=3 496163

\begin{tabular}{|c|c|c|}
\hline Characteristic & $\begin{array}{l}\text { Male } \\
\mathrm{N}=1698932 \\
\mathrm{~N}(\%)\end{array}$ & $\begin{array}{l}\text { Female } \\
N=1797231 \\
N(\%)\end{array}$ \\
\hline \multicolumn{3}{|l|}{ Age (years) } \\
\hline$<30^{*}$ & $61130(3.6)$ & $111124(6.2)$ \\
\hline $30-49$ & $744382(43.8)$ & $817577(45.5)$ \\
\hline $50-64$ & 523914 (30.9) & 501891 (27.9) \\
\hline $65-79$ & $297782(17.5)$ & $298680(16.6)$ \\
\hline $80+$ & $71724(4.2)$ & $67959(3.8)$ \\
\hline \multicolumn{3}{|l|}{ Marital status } \\
\hline Married & $1586976(93.4)$ & $1577180(87.8)$ \\
\hline Widowed & $40226(2.4)$ & $136484(7.6)$ \\
\hline Divorced & $71730(4.2)$ & $83567(4.6)$ \\
\hline \multicolumn{3}{|l|}{ Education } \\
\hline Compulsory & $291279(17.1)$ & $569561(31.7)$ \\
\hline Secondary & $867226(51.1)$ & $1003839(55.9)$ \\
\hline Tertiary & $540427(31.8)$ & $223831(12.4)$ \\
\hline \multicolumn{3}{|c|}{ Combined education (individual-spouse) } \\
\hline Tertiary-Tertiary & $148362(8.7)$ & $153263(8.5)$ \\
\hline Tertiary-Secondary & $332780(19.6)$ & $61923(3.4)$ \\
\hline Tertiary-Compulsory & $59285(3.5)$ & $8645(0.5)$ \\
\hline Secondary-Tertiary & $54767(3.2)$ & $334335(18.6)$ \\
\hline Secondary-Secondary & $562292(33.1)$ & $594904(33.1)$ \\
\hline Secondary-Compulsory & $250167(14.7)$ & $74600(4.2)$ \\
\hline Compulsory-Tertiary & $6775(0.4)$ & $58497(3.3)$ \\
\hline Compulsory-Secondary & $64382(3.8)$ & $265857(14.8)$ \\
\hline Compulsory-Compulsory & $220122(13.0)$ & 245207 (13.6) \\
\hline \multicolumn{3}{|l|}{ Nationality } \\
\hline Swiss & 1353195 (79.6) & 1491171 (83.0) \\
\hline Non-Swiss & $345737(20.4)$ & $306060(17.0)$ \\
\hline \multicolumn{3}{|l|}{ Language region } \\
\hline German & $1230048(72.4)$ & 1300651 (72.4) \\
\hline French & $391315(23.0)$ & $413932(23.0)$ \\
\hline Italian & 77569 (4.6) & $82648(4.6)$ \\
\hline \multicolumn{3}{|l|}{ Type of household } \\
\hline Single-person & $92035(5.4)$ & $142182(7.9)$ \\
\hline Multi-person & 1592907 (93.8) & 1636795 (91.1) \\
\hline Institution & $13990(0.8)$ & $18254(1.0)$ \\
\hline \multicolumn{3}{|l|}{ Urbanisation } \\
\hline Urban & $432940(25.5)$ & $464395(25.9)$ \\
\hline Peri-urban & $798370(47.0)$ & $839687(46.7)$ \\
\hline Rural & $467622(27.5)$ & 493149 (27.4) \\
\hline \multicolumn{3}{|l|}{ Religion } \\
\hline Protestant & $626613(36.9)$ & 688507 (38.3) \\
\hline Catholic & $725207(42.7)$ & $793442(44.1)$ \\
\hline No affiliation & $192658(11.3)$ & $160978(9.0)$ \\
\hline Other-unknown & $154454(9.1)$ & $154304(8.6)$ \\
\hline
\end{tabular}

Swiss National Cohort.

${ }^{*}$ Study inclusion date after census 2000 when having reached 30 years of age. 
oldest open-ended age-group (95+ years) derived from a Gompertz model. 2021

In additional analyses we compared the characteristics of the study population to ever-married persons who were excluded because of unknown educational attainment. We also examined results in the population restricted to couples married at the 2000 census, adjusted for duration of marriage based on date of marital status change (single to married) reported in 2000 census and examined effects by language region. All analyses were performed using Stata $11 .^{22}$

\section{RESULTS}

\section{Characteristics of the study population}

The 2000 census population included 7280246 individuals. We excluded 135204 persons (1.9\%) with missing data on educational attainment. We excluded a further 3648879 individuals (50.1\%) who did not meet inclusion criteria. The characteristics of the study population of 3496163 persons are listed by gender in table 1 (online supplementary file - alternative table 1). The median age (IQR) was 51.1 years (40.7-62.9) in men and 49.2 years (38.6-61.9) in women. Most individuals $(90.5 \%)$ were married at census 2000 . More males than females had a tertiary education $(31.8 \%$ vs $12.4 \%)$. The proportion of secondary and tertiary education decreased as age increased. This was most evident in the markedly decreased proportions of more highly educated females in the older age-groups. For example, among 30-49 years old women $16.7 \%$ had tertiary education compared $3.0 \%$ among those $80+$ years. Other characteristics were similar across gender.

Most men with compulsory education also had a partner with compulsory education (table 1 and see online supplementary figure S1). In contrast, over half of women with compulsory education had a partner with higher educational attainment. Gender differences were most pronounced in the highest educational levels. Only $27.5 \%$ of men with a tertiary education had a spouse with tertiary education, whereas $68.5 \%$ of tertiary educated women were also married to tertiary educated men.

Table 2 HRs with 95\% Cls for all-cause mortality by different education measures with and without adjustment for spousal education in ever-married men and women aged 30 years or older

\begin{tabular}{|c|c|c|c|c|}
\hline & \multicolumn{4}{|l|}{ Education } \\
\hline & $\begin{array}{l}\text { Individual alone } \\
\mathrm{HR}(95 \% \mathrm{Cl})\end{array}$ & $\begin{array}{l}\text { Individual controlled for spouse } \\
\text { HR }(95 \% \mathrm{Cl})\end{array}$ & $\begin{array}{l}\text { Spouse alone } \\
\text { HR }(95 \% \mathrm{Cl})\end{array}$ & $\begin{array}{l}\text { Highest in couple } \\
\mathrm{HR}(95 \% \mathrm{Cl})\end{array}$ \\
\hline \multicolumn{5}{|l|}{ Male } \\
\hline \multicolumn{5}{|l|}{$30-49$ years } \\
\hline Compulsory & 1.78 (1.64 to 1.94$)$ & 1.63 (1.49 to 1.79$)$ & 1.56 (1.43 to 1.70$)$ & 1.64 (1.49 to 1.81$)$ \\
\hline Secondary & 1.50 (1.42 to 1.59$)$ & 1.46 (1.37 to 1.55$)$ & 1.23 (1.13 to 1.33$)$ & $1.48(1.40$ to 1.56$)$ \\
\hline Tertiary & 1 & 1 & 1 & 1 \\
\hline \multicolumn{5}{|l|}{$50-64$ years } \\
\hline Compulsory & 1.74 (1.67 to 1.81$)$ & 1.52 (1.46 to 1.59$)$ & 1.67 (1.60 to 1.75$)$ & 1.71 (1.64 to 1.79$)$ \\
\hline Secondary & 1.43 (1.39 to 1.47$)$ & 1.35 (1.31 to 1.39 ) & 1.28 (1.22 to 1.34$)$ & 1.43 (1.39 to 1.47$)$ \\
\hline Tertiary & 1 & 1 & 1 & 1 \\
\hline \multicolumn{5}{|l|}{$65-79$ years } \\
\hline Compulsory & 1.51 (1.48 to 1.55$)$ & 1.37 (1.34 to 1.41$)$ & 1.48 (1.43 to 1.53$)$ & 1.53 (1.49 to 1.56$)$ \\
\hline Secondary & 1.28 (1.26 to 1.31$)$ & $1.22(1.07$ to 1.25$)$ & 1.20 (1.16 to 1.24$)$ & $1.29(1.27$ to 1.32$)$ \\
\hline Tertiary & 1 & 1 & 1 & 1 \\
\hline \multicolumn{5}{|l|}{$80+$ years } \\
\hline Compulsory & 1.24 (1.21 to 1.26$)$ & 1.17 (1.15 to 1.20$)$ & 1.22 (1.18 to 1.26$)$ & 1.25 (1.22 to 1.27$)$ \\
\hline Secondary & 1.11 (1.09 to 1.13 ) & 1.09 (1.06 to 1.11$)$ & 1.07 (1.04 to 1.11$)$ & 1.11 (1.09 to 1.13$)$ \\
\hline Tertiary & 1 & 1 & 1 & 1 \\
\hline \multicolumn{5}{|l|}{ Female } \\
\hline \multicolumn{5}{|l|}{$30-49$ years } \\
\hline Compulsory & 1.45 (1.31 to 1.61$)$ & 1.35 (1.21 to 1.50$)$ & 1.34 (1.22 to 1.48$)$ & 1.31 (1.16 to 1.47$)$ \\
\hline Secondary & 1.11 (1.02 to 1.21$)$ & 1.06 (0.97 to 1.17$)$ & 1.17 (1.09 to 1.25$)$ & $1.21(1.14$ to 1.29$)$ \\
\hline Tertiary & 1 & 1 & 1 & 1 \\
\hline \multicolumn{5}{|l|}{$50-64$ years } \\
\hline Compulsory & 1.40 (1.32 to 1.49$)$ & 1.25 (1.17 to 1.33$)$ & 1.40 (1.33 to 1.48$)$ & $1.41(1.33$ to 1.49$)$ \\
\hline Secondary & 1.15 (1.09 to 1.22$)$ & 1.09 (1.02 to 1.15$)$ & 1.24 (1.19 to 1.29$)$ & 1.25 (1.20 to 1.30$)$ \\
\hline Tertiary & 1 & 1 & 1 & 1 \\
\hline \multicolumn{5}{|l|}{$65-79$ years } \\
\hline Compulsory & $1.27(1.21$ to 1.33$)$ & 1.15 (1.09 to 1.21$)$ & 1.31 (1.27 to 1.35$)$ & 1.31 (1.26 to 1.35$)$ \\
\hline Secondary & 1.12 (1.06 to 1.17$)$ & 1.06 (1.01 to 1.12 ) & 1.17 (1.13 to 1.20$)$ & 1.17 (1.13 to 1.20$)$ \\
\hline Tertiary & 1 & 1 & 1 & 1 \\
\hline \multicolumn{5}{|l|}{$80+$ years } \\
\hline Compulsory & 1.20 (1.15 to 1.27$)$ & 1.14 (1.08 to 1.20$)$ & 1.17 (1.14 to 1.20$)$ & $1.18(1.15$ to 1.21$)$ \\
\hline Secondary & 1.10 (1.05 to 1.16$)$ & $1.07(1.02$ to 1.13$)$ & 1.09 (1.06 to 1.11$)$ & 1.09 (1.07 to 1.12$)$ \\
\hline Tertiary & 1 & 1 & 1 & 1 \\
\hline
\end{tabular}




\section{Mortality by educational attainment}

During 26321153 person-years of follow-up 285013 deaths from all causes were recorded, including 88073 deaths from any type of cancer; 17097 lung cancer deaths; 9026 colorectal cancer deaths; 6671 breast cancer deaths; 8536 prostate cancer deaths; 3110 stomach cancer deaths; 102333 deaths from cardiovascular diseases; 14540 deaths from myocardial infarction; 16357 deaths from stroke; 17647 deaths from respiratory diseases; 1743 deaths from transport accidents; 5740 suicides and 9606 alcohol-related deaths. Table 2 shows HRs for all-cause mortality using three-category education measures with and without controlling for spousal educational attainment. Results varied by model and interaction terms for individual-spousal education were statistically significant.

Figure 1 shows HRs and 95\% CIs for all-cause, all-cancer and cardiovascular mortality for ever-married men by nine categories of combined educational attainment and age. Figure 2 shows the corresponding data for women. Both in men and women all-cause, all-cancer and cardiovascular mortality was inversely related to combined marital education, with mortality decreasing with higher individual attainment, and within groups of individual educational attainment, with increasing spousal education. For example, compared to men with tertiary education married to women with tertiary education, the HR for allcause mortality in men aged 65-79 years with compulsory education who were married to women with compulsory schooling was $1.70(1.63-1.78)$ but $1.34(1.13-1.58)$ for men of the same age with compulsory education married to women with tertiary education and $1.19(1.10-1.27)$ in men with secondary education married to women with tertiary education. The difference in all-cancer mortality is likely a reflection of the different patterns of cancer in women and men, with breast cancer (less strongly associated with SEP) dominating in women. All HRs and $95 \%$ CIs shown in figures 1 and 2 are also given in online supplementary tables S1 and S2 and additional cause-specific mortality in supplementary tables S3-S5.

\section{Life expectancy by educational attainment}

Table 3 shows remaining life expectancy by marital educational attainment and gender for selected ages. Both for men and women the spouse's education had a positive (if tertiary) or negative (if compulsory) association with life expectancy for all educational levels, gender, and ages. For example, the estimated remaining life expectancy in tertiary educated men aged
Figure 1 HRs with $95 \%$ Cls for all-cause, all-cancer and cardiovascular mortality in ever-married men aged 30 years or older across categories of combined marital education. Swiss National Cohort 2001-2008.
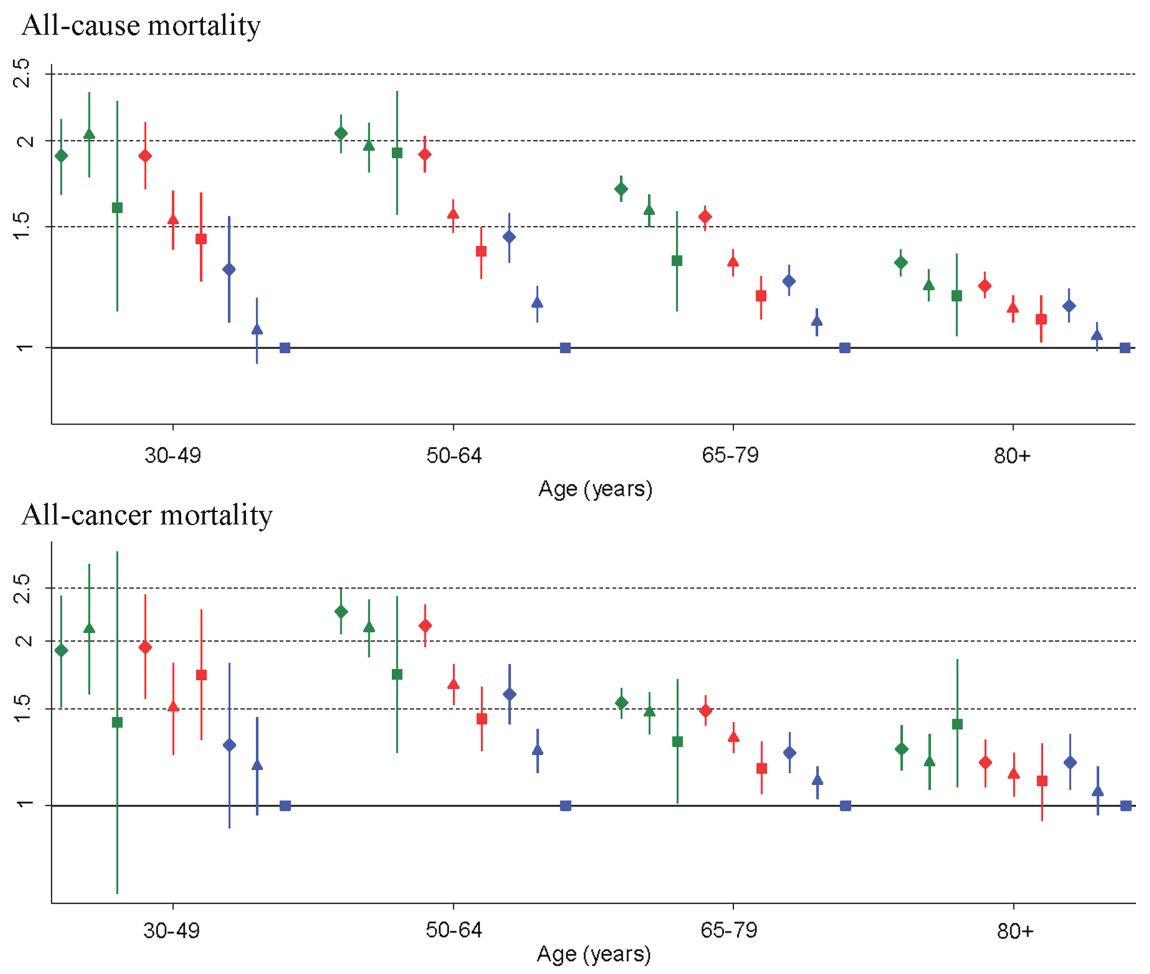

Cardiovascular mortality

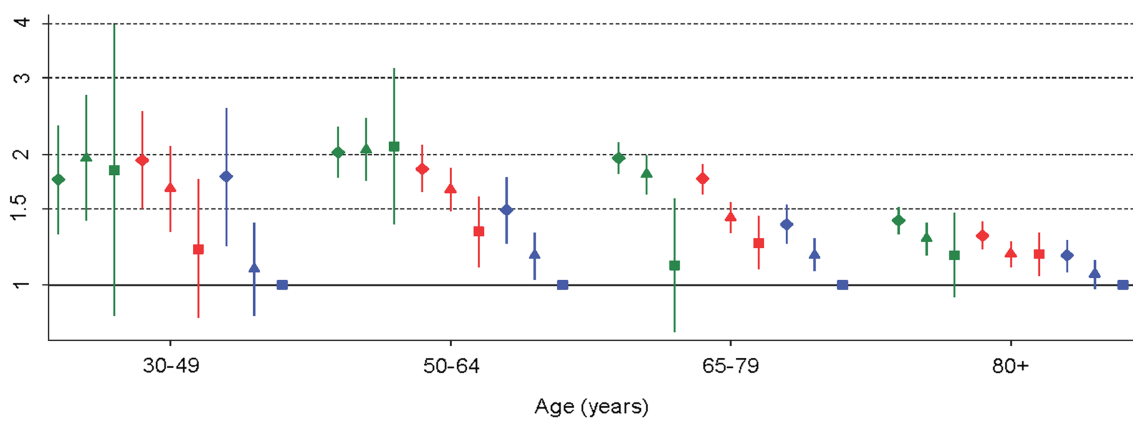

Age (years) 
30 years married to women with tertiary education was 4.6 years longer than in men with compulsory education married to women with compulsory education. The corresponding differences in life expectancy for men aged 50,65 and 80 years and older were 4.2, 3.4 and 1.6 years, respectively. They were smaller in women: 2.9, 2.8, 2.4 and 1.6 years at ages $30,50,65$ and $80+$ years.

\section{Additional analyses}

The characteristics of the study population included in the main analysis and the 102299 excluded because of unknown combined educational attainment were similar (see online supplementary table S5). Results were closely similar when restricting analyses to couples married at 2000 census (see online supplementary tables S6 and S7) and remained substantially unchanged when adjusted for duration of marriage. Stratified analyses showed no significant effects by language region (see online supplementary tables S8 and S9).

\section{DISCUSSION}

In this study mortality in ever-married persons was not only associated with their individual educational attainment but also with their spouse's education. We found that mortality decreased and life expectancy increased the higher the spouse's education was. This finding was evident for all-cause mortality and many but not all specific causes of death and was present in men and women, and across age-groups. The different mortality rates translated into substantial differences in estimated life expectancy. What was new in this study is that mortality risk and life expectancy varied by spouse's educational attainment within individual education levels. These results emphasise the potential importance of incorporating combined educational levels of married pairs in epidemiologic research.

This is one of few population-based studies investigating differences in mortality risk by categories of combined educational attainment. $^{10-12} 2324$ To our knowledge this is the first study done in a national population-based sample and examining life expectancy. Our results are consistent with previous studies. For example, a wife's education was the only spousal SEP indicator
Figure 2 HRs with $95 \%$ Cls for all-cause, all-cancer and cardiovascular mortality in ever-married women aged 30 years or older across categories of combined marital education. Swiss National Cohort 2001-2008.
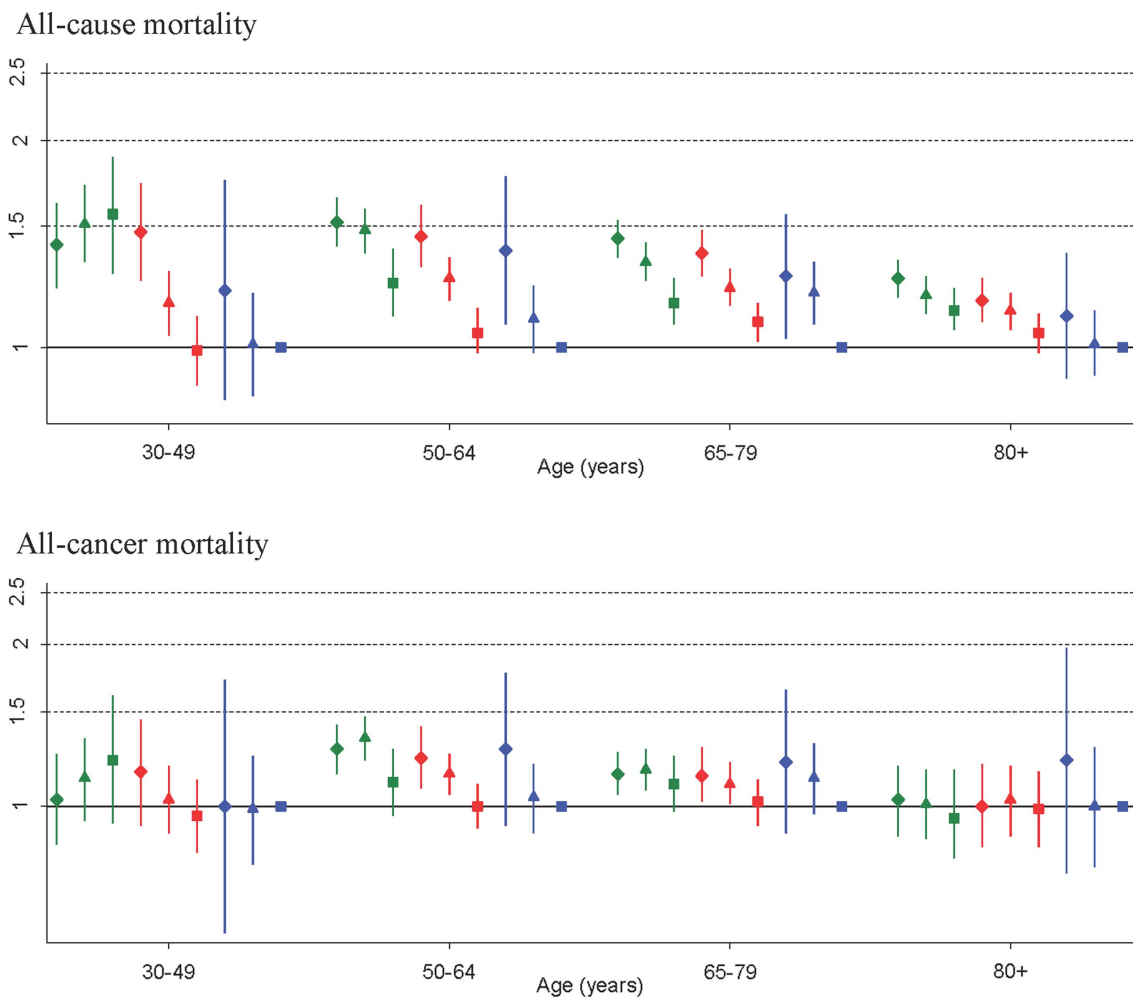

Cardiovascular mortality

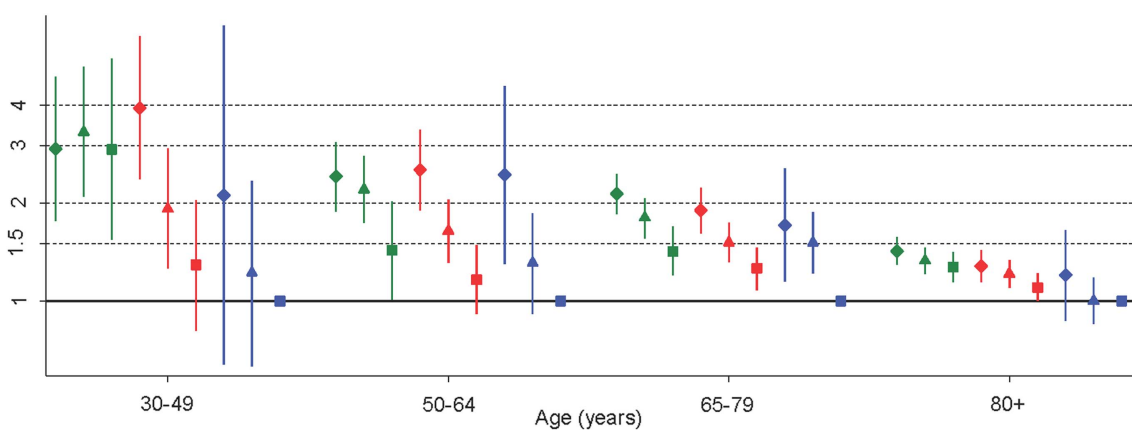

blue $=$ individual tertiary
square= spouse tertiary $\quad$ A $\quad \begin{aligned} & \text { red }=\text { individual secondary } \\ & \text { triangle }=\text { spouse secondary }\end{aligned}$ 
associated with mortality across all causes of death except stroke in Norwegian men. ${ }^{11}$ Results from Israeli and Swedish studies also showed important mortality differences by controlling for spouse's education. ${ }^{12} 24$ Our results were most similar to Jaffe et al who examined differences in married pairs' education and found that a husband's risk of dying was inversely related to his wife's education. ${ }^{24}$ Egeland et al also found an inverse relationship between a wife's education and a husband's cardiovascular mortality, concluding that a spouse's education level can add valuable information to epidemiologic investigations. ${ }^{23}$ Recent studies in the USA have shown that income may be a better predictor of mortality than education, and that education matters more for a woman's self-rated health than a man's but has a stronger effect on men's mortality. ${ }^{25} 26$ Skalicka et al found that a wife's education was associated with a husband's all-cause mortality but a husband's occupation and income (not education) were more specifically related to a wife's cardiovascular and lung cancer mortality. ${ }^{11}$ Disentangling the effects of different SEP measures, comparing effects across studies, and deciding which measures and what level to use in epidemiological research is a challenge.

A married couples' combined education may function as a proxy measure for shared resources, lifestyles and health behaviours. Effects of spousal education seem to persist over the life course. We found regardless of age the difference in life expectancy associated with a wife's education is generally similar to or larger than the difference in life expectancy associated with a husband's education. However, differences in all-cause and cause-specific HRs generally lessened with age as indicated by a smaller range of HRs in the $80+$ age-group. A potential explanation for the decreased range of HRs in older persons may be that with increasing age socio-economic factors become less important, and genetic factors more important. It may also be related equilibration of both shared material resources and social privilege. In this study most persons $>65$ years old were married $>20$ years. The effect of a spouse's higher educational attainment might moderate over long periods of living together. Because Switzerland has federally mandated health insurance, it is unlikely any age-specific effects were due to any systemic differences in access to care. Likewise education is generally fixed by early-adulthood and therefore not affected by changes in health status over the life course.

The use of combined educational attainment has some advantages over income and occupation. Income information is not as widely collected as education and considered more sensitive in epidemiological research. For example, income information was not available for this study because it is not collected in the Swiss census. Income is also liable to change over follow-up. In many cases older women may never have had an individual income to report. Like income, occupation may change with time. It may also not accurately reflect an older person's SEP (ie, retirement does not reflect SEP and many older women never worked outside the home). Additionally, differences in material resources and social privilege do not directly or uniquely translate to distinct occupational categories. Our study suggests that taking the combined education of ever-married persons into account could potentially strengthen the description and interpretation of the effects of education (as SEP measure) on mortality risk and life expectancy. It does not, however, investigate the effects of combined education on other outcomes or uses beyond epidemiological research. We also acknowledge that our nine-category measure, albeit simple to employ, may not be the only or best methodological approach to account for important variations in health outcomes.

There are a number of strengths and weaknesses of this research. Major strengths are the population base of the study

Table 3 Life expectancy by combined marital education of ever-married men and women at selected ages

\begin{tabular}{|c|c|c|c|c|}
\hline & \multicolumn{4}{|l|}{ Life expectancy at age } \\
\hline & $\begin{array}{l}30 \text { years } \\
\text { Remaining years of life }(95 \% \mathrm{Cl})\end{array}$ & 50 years & 65 years & 80 years \\
\hline \multicolumn{5}{|l|}{ Male } \\
\hline Tertiary-Tertiary & 53.3 (53.1 to 53.5 ) & 33.9 (33.7 to 34.1$)$ & 20.4 (20.2 to 20.6) & 9.0 (8.8 to 9.2 ) \\
\hline Tertiary-Secondary & 52.5 (52.4 to 52.6 ) & 33.2 (33.1 to 33.3 ) & 19.9 (19.7 to 20.0$)$ & 8.8 (8.7 to 8.9$)$ \\
\hline Tertiary-Compulsory & 51.0 (50.8 to 51.3 ) & 31.8 (31.6 to 32.1 ) & 18.9 (18.7 to 19.0$)$ & 8.2 (8.1 to 8.3 ) \\
\hline Secondary-Tertiary & 51.5 (51.2 to 51.9$)$ & 32.5 (32.1 to 32.8 ) & 19.4 (19.1 to 19.7$)$ & 8.5 (8.2 to 8.8 ) \\
\hline Secondary-Secondary & 50.7 (50.6 to 50.8 ) & 31.6 (31.5 to 31.7 ) & 18.7 (18.6 to 18.8$)$ & $8.2(8.1$ to 8.3$)$ \\
\hline Secondary-Compulsory & 49.1 (49.0 to 49.3 ) & 30.2 (30.1 to 30.3 ) & 17.7 (17.6 to 17.8$)$ & 7.8 (7.7 to 7.8$)$ \\
\hline Compulsory-Tertiary & 50.2 (49.3 to 51.1$)$ & 31.2 (30.3 to 32.0 ) & 18.7 (17.9 to 19.4 ) & 8.2 (7.6 to 8.8 ) \\
\hline Compulsory-Secondary & 49.1 (48.8 to 49.3 ) & 30.2 (30.0 to 30.4 ) & 17.7 (17.5 to 17.9$)$ & 7.9 (7.7 to 8.0$)$ \\
\hline Compulsory-Compulsory & 48.7 (48.6 to 48.9 ) & 29.7 (29.6 to 29.8 ) & 17.0 (17.0 to 17.1$)$ & 7.4 (7.3 to 7.4$)$ \\
\hline \multicolumn{5}{|l|}{ Female } \\
\hline Tertiary-Tertiary & 57.1 (56.8 to 57.3 ) & 37.6 (37.3 to 37.9$)$ & 23.7 (23.4 to 24.0$)$ & 11.2 (10.9 to 11.5$)$ \\
\hline Tertiary-Secondary & 56.1 (55.7 to 56.6$)$ & 36.7 (36.3 to 37.1 ) & 23.0 (22.6 to 23.4 ) & 11.0 (10.6 to 11.4$)$ \\
\hline Tertiary-Compulsory & 55.1 (54.1 to 56.1 ) & 35.7 (34.8 to 36.7 ) & 22.3 (21.4 to 23.3 ) & 10.5 (9.6 to 11.5$)$ \\
\hline Secondary-Tertiary & 56.6 (56.4 to 56.7 ) & 37.1 (36.9 to 37.2 ) & 23.3 (23.1 to 23.4 ) & $10.9(10.8$ to 11.0$)$ \\
\hline Secondary-Secondary & 55.5 (55.4 to 55.5 ) & 36.1 (36.0 to 36.1 ) & 22.5 (22.4 to 22.5 ) & 10.3 (10.3 to 10.4$)$ \\
\hline Secondary-Compulsory & 54.4 (54.1 to 54.6 ) & 35.1 (34.9 to 35.3 ) & 21.7 (21.5 to 21.9) & 10.0 (9.8 to 10.2$)$ \\
\hline Compulsory-Tertiary & 55.5 (55.3 to 55.8 ) & 36.3 (36.0 to 36.5 ) & 22.6 (22.4 to 22.8 ) & $10.4(10.2$ to 10.5$)$ \\
\hline Compulsory-Secondary & 54.5 (54.4 to 54.6 ) & 35.2 (35.1 to 35.3 ) & 21.8 (21.7 to 21.9 ) & $9.9(9.8$ to 10.0$)$ \\
\hline Compulsory-Compulsory & 54.2 (54.1 to 54.3$)$ & 34.8 (34.7 to 34.9 ) & 21.3 (21.2 to 21.4$)$ & 9.6 (9.5 to 9.6$)$ \\
\hline
\end{tabular}

Swiss National Cohort, 2001-2008. 
and the consistency of our findings with other studies supporting generalisability. Given the large sample size our main findings had statistical precision while we were able to conduct thorough stratified and additional analyses supporting our main results. A general limitation of the SNC is that linkage is less successful in adolescents and younger adults, who are a highly mobile group. ${ }^{13}$ This was not an issue in the present study that focussed on married couples $>30$ years or old and their level of education. We were unable to characterise health and lifestyle factors such as smoking, levels of exercise or diet. Another limitation is the lack of information on individual financial resources in the SNC. Lastly, we were only able to evaluate duration of marriage in persons married at the 2000 census. Thus we could not identify how long persons were married if they were divorced or widowed, whether or not they were previously married and if so for how long. Therefore, some uncertainty (in these limited cases) remains, possibly introducing a nondifferential bias attenuating true effects.

In conclusion, the use of individual educational attainment, although commonplace, may not provide a good estimate of the true effect of a household's level of education on mortality risk and life expectancy. These findings are relevant to epidemiologic research into effects of social, economic and behavioural factors on health that may be associated with and mediated by education, and for research into specific exposures, for example, air pollution, which may be confounded by education. Researchers should consider collecting information on the education level of married pairs whenever possible. A more detailed understanding of persons' living situations, which is not only based on marital status and individual education, will inform public health strategies to reduce health disparities.

\section{What is already known on the subject}

Education is typically measured by highest achieved educational level of an individual, which does not account for the shared nature of material resources, lifestyle and social position of the household.

\section{What this study adds}

Use of individual educational attainment, although commonplace, may not provide a good estimate of the true effect of a household's level of education on mortality and life expectancy. This is relevant to epidemiologic research into effects of social, economic and behavioural factors on health that may be associated with and mediated by education, and for research into specific exposures, which may be confounded by education.

Collaborators This manuscript contains original material not previously published and made possible with support from the members of the SNC Study Group: Matthias Egger (Chairman of the Executive Board—Bern, Switzerland), Milo Puhan (Chairman of the Scientific Board-Zurich, Switzerland), Matthias Bopp (Zurich, Switzerland), Adrian Spoerri, Marcel Zwahlen (Bern, Switzerland); Nino Kuenzli (Basel, Switzerland); Fred Paccaud (Lausanne, Switzerland); and Michel Oris (Geneva, Switzerland).

Contributors Authors have contributed significantly to the work as follows: conception/design (all); acquisition of data (AS and ME), analysis (AS, KS and KC), interpretation (all). All of the authors have critically contributed to the drafting and revising of the manuscript for important intellectual content and have approved the manuscript for exclusive submission to JECH.

Funding This work was supported by funds from the Swiss National Science Foundation (grant number 33CSC0_134273).

\section{Competing interests None.}

Ethics approval The Bern and Zurich cantonal ethics committees approved the SNC with approval covering the present analysis.

Provenance and peer review Not commissioned; externally peer reviewed.

Data sharing statement Any unpublished data are available upon request via email to the corresponding author.

\section{REFERENCES}

1 Kaufman JS. Social epidemiology. In: Rothman KJ, Greenland S, Lash TL. eds. Modern epidemiology. 3rd edn. Philadelphia, PA, USA: Lippincott Williams \& Wilkins, 2008:532-48.

2 Johnson W, Kyvik KO, Mortensen EL, et al. Does education confer a culture of healthy behavior? Smoking and drinking patterns in Danish twins. Am J Epidemiol 2011;173:55-63.

3 Greenlund $\mathrm{KJ}$, Liu $\mathrm{K}$, Kiefe $\mathrm{Cl}$, et al. Impact of father's education and parental smoking status on smoking behavior in young adults. The CARDIA study. Coronary Artery Risk Development in Young Adults. Am J Epidemiol 1995; 142:1029-33.

4 Comparative Report of Health Literacy in Eight EU Member States. The European Health Literacy Survey HLS-EU. 2012. http://www.health-literacy.eu

5 Erikson R, Torssander J. Clerics die, doctors survive: a note on death risks among highly educated professionals. Scand J Public Health 2009;37:227-31.

6 Jemal A, Thun MJ, Ward EE, et al. Mortality from leading causes by education and race in the United States, 2001. Am J Prev Med 2008;34:1-8.

7 Lahelma E, Laaksonen M, Aittomaki A. Occupational class inequalities in health across employment sectors: the contribution of working conditions. Int Arch Occup Environ Health 2009;82:185-90.

8 Chandola T, Bartley M, Wiggins $R$, et al. Social inequalities in health by individual and household measures of social position in a cohort of healthy people. J Epidemiol Community Health 2003;57:56-62.

9 Galobardes B, Lynch J, Smith GD. Measuring socioeconomic position in health research. Br Med Bull 2007;81-82:21-37.

10 Jaffe DH, Eisenbach Z, Neumark YD, et al. Does one's own and one's spouse's education affect overall and cause-specific mortality in the elderly? Int J Epidemiol 2005;34:1409-16.

11 Skalicka V, Kunst AE. Effects of spouses' socioeconomic characteristics on mortality among men and women in a Norwegian longitudinal study. Soc Sci Med 2008;66:2035-47.

12 Torssander J, Erikson R. Marital partner and mortality: the effects of the social positions of both spouses. J Epidemiol Community Health 2009;63:992-8.

13 Bopp M, Spoerri A, Zwahlen M, et al. Cohort Profile: the Swiss National Cohort-a longitudinal study of 6.8 million people. Int J Epidemiol 2009;38:379-84.

14 Spoerri A, Zwahlen M, Egger M, et al. The Swiss National Cohort: a unique database for national and international researchers. Int J Public Health 2010;55:239-42.

15 Fair M. Generalized record linkage system-Statistics Canada's record linkage software. Austrian J Stat 2004;33:37-53.

16 Fellegi IP, Sunter AB. A theory of record linkage. J Am Stat Assoc 1969;64:1183-210.

17 Eidgenössische Volkszählung 2000. Abschlussbericht zur Volkszählung 2000. 2005. http://www.bfs.admin.ch/bfs/portal/de/index/themen/01/06/blank/key/05/01. Document.20603.xls.

18 Renaud A. Methodology Report-Coverage Estimation for the Swiss Population Census 2000. Neuchâtel, Switzerland: Swiss Federal Statistical Office, 2004.

19 Swiss Federal Statistical Office. Statistical encyclopaedia. 2012. http://www.bfs. admin.ch/bfs/portal/de/index/infothek/lexikon/lex/0.Document.20603.xls

20 Chiang CL. The life table and its applications. Malabar, FL: Robert E. Krieger Publishing Company, 1984.

21 Hsieh JJ. A general theory of life table construction and a precise abridged life table method. Biom J 1991;33:143-62.

22 StataCorp. Stata Statistical Software: Release 11. College Station, TX: StataCorp LP 2009.

23 Egeland GM, Tverdal A, Meyer HE, et al. A man's heart and a wife's education: a 12-year coronary heart disease mortality follow-up in Norwegian men. Int J Epidemiol 2002;31:799-805.

24 Jaffe DH, Eisenbach Z, Neumark YD, et al. Effects of husbands' and wives' education on each other's mortality. Soc Sci Med 2006;62:2014-23.

25 Sabanayagam C, Shankar A. Income is a stronger predictor of mortality than education in a national sample of US adults. J health Popul Nutr 2012;30:82-6.

26 Ross CE, Masters RK, Hummer RA. Education and the gender gaps in health and mortality. Demography 2012;49:1157-83. 